\title{
PENGARUH TINGKAT SUKU BUNGA TERHADAP JUMLAH NASABAH KREDIT KONSUMTIF PADA PT. BANK PERKREDITAN RAKYAT (BPR) SURYAJAYA KUBUTAMBAHAN TAHUN 2013- 2015
}

\author{
Ketut Lina Astiani \\ Jurusan Akuntansi Program Diploma III, \\ Universitas Pendidikan Ganesha, Singaraja \\ Linaastiani@yahoo.com
}

\begin{abstract}
Abstrak
Penelitian ini bertujuan Untuk mengetahui Pengaruh Tingkat Suku Bunga Terhadap Jumlah Nasabah Kredit Konsumtif pada PT. Bank Perkreditan Rakyat (BPR) Suryajaya Kubutambahan Tahun 2013-2015. Data dikumpulkan menggunakan metode dokumentasi dan wawancara, serta penelitian ini menggunakan analisis kuantitatif, yaitu tingkat suku bunga kredit konsumtif tahun 2013-2015, dan jumlah nasabah kredit konsumtif tahun 2013-2015.Data dianalisis dengan menggunakan teknik analisis data kuantitatif.

Hasil penelitian menunjukkan ada pengaruh antara tingkat suku bunga terhadap jumlah nasabah kredit konsumtif pada PT. Bank Perkreditan Rakyat (BPR) Suryajaya Kubutambahan. Jumlah nasabah kredit konsumtif dipengaruhi oleh tingkat suku bunga sebesar 5,3\% dan 94,7\% dipengaruhi oleh faktor lain. Terdapat hubungan antara tingkat suku bunga terhadap jumlah nasabah kredit konsumtif pada PT. Bank Perkreditan Rakyat (BPR) Suryajaya Kubutambahan
\end{abstract}

Kata kunci: Suku Bunga, Nasabah, Kredit,

Abstract

This study aims to know the effect of the rate of interest to Total Customer Consumer Credit at PT. Rural Banks (BPR) Suryajaya Kubutambahan Year 2013-2015. Data were collected using the method of documentation and interviews, as well as the study used quantitative analysis, namely consumer credit interest rates in 2013-2015, and the number of consumer loan customers in 20132015.Data analyzed using quantitative data analysis techniques.

Results showed no effect between the interest rate on the amount of consumer credit customers at PT. Rural Banks (BPR) Suryajaya Kubutambahan. The number of customers affected by the consumer credit interest rate of $5.3 \%$ and $94.7 \%$ influenced by other factors. There is a real connection between the interest rate on the amount of consumer credit customers at PT. Rural Banks (BPR) Suryajaya Kubutambahan

Keywords: Interest Rates, Customer, Credit,

\section{Pendahuluan}

Dalam kaitan pembangunan ekonomi di masyarakat, telah disadari hambatan yang dihadapi adalah keterbatasan modal ataupun sumber daya keuangan. Bank Perkreditan Rakyat adalah bank yang melaksanakan kegiatan usaha secara konvensional atau berdasarkan prinsip syariah yang dalam kegiatannya tidak memberikan jasa dalam lalu lintas pembayaran. PT. Bank Perkreditan Rakyat (BPR) Suryajaya Kubutambahan merupakan lembaga keuangan yang berfungsi melayani golongan pengusaha mikro, kecil dan menengah dengan lokasi yang pada umumnya dekat dengan tempat masyarakat yang membutuhkan. Dalam praktek bank, kredit adalah suatu pemberian pinjaman oleh bank kepada nasabah untuk membiayai kegiatan usahanya dalam jumlah tertentu dan dalam jangka waktu tertentu.

Tingkat suku bunga kredit konsumtif PT. Bank Perkreditan Rakyat (BPR) Suryajaya Kubutambahan yang berlaku relatif berubah dari tahun ke tahun sesuai dengan kondisi dan keadaan yang ditentukan. Suku bunga dapat diartikan sebagai balas jasa yang diberikan 
oleh Bank atau Lembaga Keuangan lainnya kepada nasabah yang membeli atau menjual produknya. Bunga juga dapat diartikan sebagai harga yang harus dibayar kepada nasabah (yang memiliki simpanan) dan yang harus dibayar oleh nasabah kepada Bank (yang memiliki pinjaman). Baik bunga simpanan maupun bungan pinjaman merupakan komponen utama faktor biaya dan pendapatan bagi Bank. Bunga simpanan merupakan biaya dana yang harus dikeluarkan kepada nasabah sedangkan bunga pinjaman pendapatan yang diterima dari nasabah. Antara bunga simpanan dan bunga pinjaman masing-masing saling mempengaruhi satu sama lainnya. Apabila bunga simpanan tinggi, maka secara otomatis bunga pinjaman juga terpengaruh ikut naik dan demikian pula sebaliknya. Dalam hal ini, agar keuntungan yang diperoleh dapat maksimal maka pihak manajemen bank harus pandai dalam menentukan besar kecilnya komponen suku bunga maka akan dapat merugikan bank itu sendiri.

\section{Metode Penelitian}

Lokasi penelitian ini dilakukan di PT. Bank Perkreditan Rakyat (BPR) Suryajaya Kubutambahan yang beralamat di Jalan Raya Kubutambahan Singaraja Buleleng. Dalam penulisan laporan ini yang dijadikan subjek dari penelitian ini adalah PT. Bank Perkreditan Rakyat (BPR) Suryajaya Kubutambahan. Dan objek penelitian ini adalah tingkat suku bunga kredit konsumtif dan jumlah nasabah kredit konsumtif pada PT. Bank Perkreditan Rakyat (BPR) Suryajaya Kubutambahan. Jenis data yang digunakan adalah data kuantitatif maka sasarannya adalah tingkat suku bunga kredit konsumtif dan jumlah nasabah kredit konsumtif pada PT. Bank Perkreditan Rakyat (BPR) Suryajaya Kubutambahan. Sumber data yang digunakan dalam penelitian ini adalah data primer dan data sekunder. Data primer adalah data yang hanya dapat kita peroleh dari sumber asli atau pertama. Data primer yang bersumber dari PT. Bank Perkreditan Rakyat (BPR) Suryajaya Kubutambahan dari karyawan

Data yang dibutuhkan dalam penelitian ini dikumpulkan dengan cara menerapkan berbagai teknik pengumpulan data, yaitu Teknik Wawancara yaitu teknik pengumpulan data yang dilakukan dengan mengadakan wawancara ataupun tanya jawab secara langsung dengan staf karyawan dibagian pemasaran PT. Bank Perkreditan Rakyat (BPR) Suryajaya Kubutambahan yang dapat memberikan informasi tentang tingkat suku bunga dan jumlah nasabah kredit konsumtif. Teknik Dokumentasi yaitu Yaitu teknik pengumpulan data yang dilakukan oleh peneliti dengan mengumpulkan dokumen-dokumen dan mencatat data-data yang diperlukan serta digunakan untuk memperoleh data tentang tingkat suku bunga kredit konsumtif dan jumlah nasabah kredit konsumtif. dan Studi Kepustakaan yaitu teknik pengumpulan data yang dilakukan dengan jalan mencari bahan-bahan dari literatur sumber pustaka yang berhubungan dengan permasalahan yang tertuang pada judul penelitian. Dalam penelitian ini analisis data yang digunakan adalah teknik Analisis Deskriptif Kuantitatif yaitu metode analisis data yang menekankan pada pengujian teori melalui pengukuran data yang dinyatakan dalam satuan angka-angka, yang menekankan pada pengujian teori melalui pengukuran terhadap variabel serta melakukan analisis data dengan prosedur statistik.

a. Analisis Koreelasi Sederhana

Analisis ini digunakan untuk menganalisis hubungan antara tingkat suku bunga

kredit konsumtif terhadap jumlah nasabah kredit konsumtif.

$$
r_{x y}=\frac{N \sum \mathrm{XY}-\left(\sum \mathrm{X}\right)\left(\sum \mathrm{Y}\right)}{\sqrt{\left[N \sum \mathrm{x}^{2}-(X)^{2}\right]\left[N \sum \mathrm{Y}^{2}-\left(\sum \mathrm{Y}^{2}\right)\right]}}
$$

\section{b. Koefisien Determinasi}

Analisis koefisien determinasi meerupakan variasi ukuran yang dapat menjelaskan tentang besarnya sumbangan atau andil dari pengaruh tingkat suku bunga kredit konsumtif terhadap jumlah nasabah kredit konsumtif.

$$
R^{2}=r^{2} \times 100 \%
$$

c. Analisis t-test

Uji $t$,merupakan alat analisis yang digunakan untuk menguji atau menngetahui berapa besarnya hubungan dua variabel. 


$$
t=\frac{r \sqrt{n-2}}{\sqrt{1-r^{2}}}
$$

Dimana:

$\mathrm{t}=\mathrm{t}$-test

$r=$ Koefisien Korelasi

$r^{2} \quad=$ Koefisien Korelasi

$\mathrm{n} \quad=$ Sampel

Langkah- langkah pengujian Hipotesis diatas adalah sebagai berikut:

1. Hipotesis Statistik

$$
\begin{aligned}
& \mathrm{Ho}=0 \\
& \mathrm{Ho} \neq 0
\end{aligned}
$$

2. Keputusan pengujian

a. Menolak Ho apabila $t$ hitung $\geq t$ tabel, artinya ada pengaruh signifikan dari $X$ terhadap $\mathrm{Y}$

b. Menerima Ho apabila $t$ hitung $\leq \mathrm{t}$ tabel, artinya tidak ada pengaruh signifikan dari $X$ terhadap $Y$

\section{Hasil Penelitian}

\section{Prosedur Pembayaran Dana Pensiun Pada PT. Bank Pembangunan Daerah Bali Cabang Singaraja.}

a. Analisis Korelasi Sederhana

Analisis ini digunakan untuk menganalisis hubungan antara tingkat suku bunga kredit konsumtif terhadap jumlah nasabah kredit konsumtif. Perhitungan koefisien korelasi pengaruh tingkat suku bunga terhadap jumlah nasabah kredit konsumtif dapat dilihat dalam tabel 4.3 berikut.

diketahui bahwa :

$$
\begin{aligned}
& \sum \mathrm{X}=5,725 \\
& \sum \mathrm{Y}=11.444 \\
& \sum \mathrm{XY}=1.761,62 \\
& \sum \mathrm{x}^{2}=1,05 \\
& \sum \mathrm{Y}^{2}=4.081 .778 \\
& \mathrm{~N}=36 \\
& \mathrm{Maka}, \\
& r_{x y}=\frac{N \sum \mathrm{XY}-\left(\sum \mathrm{X}\right)\left(\sum \mathrm{Y}\right)}{\sqrt{\left[N \sum \mathrm{X}^{2}-(X)^{2}\right]\left[N \sum \mathrm{Y}^{2}-\left(\sum \mathrm{Y}^{2}\right)\right]}} \\
& \frac{(36)(1.761,62)-(5,725)(11.444)}{\sqrt{\left[(36)(1,05)-(5,725)^{2}\right]\left[(36)(4.081 .778)-(11.444)^{2}\right.}} \\
& =\frac{-2.098,58}{\sqrt{80.277 .853}}
\end{aligned}
$$




$$
\begin{aligned}
& =\frac{-2.098,58}{8.959,79} \\
& =-0,2342
\end{aligned}
$$

Jadi, dari perhitungan diatas didapatkan korelasi sebesar -0,2342 artinya adanya korelasi negative sebesar 0,2342 . Ini berarti bahwa ada hubungan yang negative. Hal ini berarti apabila tingkat suku bunga kredit konsumtif meningkat maka jumlah nasabah kredit konsumtif akan menurun dan begitu juga sebaliknya apabila tingkat suku bunga kredit konsumtif menurun maka jumlah nasabah kredit konsumtif akan meningkat.

b. Koefisien Determinasi

Analisis koefisien determinasi meerupakan variasi ukuran yang dapat menjelaskan tentang besarnya sumbangan atau andil dari pengaruh tingkat suku bunga kredit konsumtif terhadap jumlah nasabah kredit konsumtif. Perhitungan koefisien determinasi adalah sebagai berikut ;

Dimana diketahui :

$$
\begin{aligned}
r & =0,2342 \\
R^{2} & =r^{2} \times 100 \% \\
& =(-0,02342)^{2} \times 100 \% \\
& =0,053 \times 100 \% \\
& =5,3 \%
\end{aligned}
$$

Jadi, Koefisien determinasi didapatkan sebesar 5,3\%, ini berarti jumlah nasabah kredit konsumtif dipengaruhi oleh tingkat suku bunga sebesar 5,3\% dan sisanya 94,7 dipengaruhi oleh faktor jaminan.

a. Uji t

Pengujian dengan menggunakan uji-t digunakan mengenai apakah tingkat suku bunga kredit konsumtif berpengaruh terhadap jumlah nasabah kredit konsumtif.

1. Formulasi Hipotesis

$\mathrm{Ho}=0$, artinya tidak ada pengaruh antara tingkat suku bunga kredit konsumtif $(X)$ terhadap jumlah nasabah kredit konsumtif $(Y)$.

$\mathrm{Ho} \neq 0$, artinya ada pengaruh antara tingkat suku bunga kredit konsumtif $(X)$ terhadap jumlah nasabah kredit konsumtif $(Y)$.

2. Menentukan tingkat kepercayaan ( $t$-tabel dua sisi dengan huruf nyata, $\alpha=0,05$ ).

$$
\begin{aligned}
& \mathrm{n}=36 \\
& \mathrm{df}=\mathrm{N}-1=35 \\
& \text { t0,05;n-k=1,684 } \\
& \text { t0,05;36- } 1=1,684
\end{aligned}
$$

3. Perhitungan t-hitung

Sebelum mengetahui apakah Ho ditolak atau Ho diterima terlebih dahulu akan dihitung berapa besar t-hitungnya yaitu sebagai berikut:

$$
\begin{aligned}
& \text { t-hitung }=\frac{r \cdot \sqrt{n-2}}{\sqrt{1-r}} \\
& =\frac{-0,2342 \cdot \sqrt{36-2}}{\sqrt{1-(-0,2342)^{2}}} \\
& =\frac{-0,2342 \cdot \sqrt{34}}{\sqrt{1-0,055}}
\end{aligned}
$$


Vol. 8 No.1. JULI 2017

p-ISSN: 2338-6177

$=\frac{(-0,2342) \cdot(5,831)}{\sqrt{0,945}}$

$=\frac{-1,366}{0,972}$

$=-1,405$

Jadi, t-hitung didapatkan sebesar -1,405 dan t-tabel sebesar -1,684. Karena t-hitung lebih besar dari t-tabel, maka $\mathrm{Ho}=0$ kita tolak, ini berarti ada hubungan antara tingkat suku bunga kredit konsumtif $(\mathrm{x})$ dengan jumlah nasabah kredit konsumtif $(\mathrm{y})$.

\section{Pembahasan}

\section{Pengaruh Tingkat Suku Bunga Terhadap Jumlah Nasabah pada PT. Bank Perkreditan} Rakyat Suryajaya Kubutambahan

Bank Perkreditan Rakyat adalah bank yang melaksanakan kegiatan usaha secara konvensional atau berdasarkan prinsip syariah yang dalam kegiatannya tidak memberikan jasa dalam lalu lintas pembayaran. Kegiatan Bank Perkreditan Rakyat jauh lebih sempit jika dibandingkan dengan kegiatan bank umum. Bank Perkreditan Rakyat dalam melakukan kegiatannya tidak sama dengan kegiatan yang dilakukan oleh bank konvensional (bank umum)

Bank Perkreditan Rakyat (BPR) Suryajaya Kubutambahan merupakan lembaga keuangan yang berfungsi melayani golongan pengusaha mikro, kecil dan menengah dengan lokasi yang pada umumnya dekat dengan tempat masyarakat yang membutuhkan. Dalam praktek bank, kredit adalah suatu pemberian pinjaman oleh bank kepada nasabah untuk membiayai kegiatan usahanya dalam jumlah tertentu dan dalam jangka waktu tertentu. Adapun Kredit Konsumtif yaitu kredit yang diberikan kepada perseorangan untuk keperluan konsumtif. Kredit konsumtif sebagai pinjaman yang diberikan oleh bank kepada nasabah untuk meningkatkan kesejahteraan dan untuk memenuhi kebutuhan hidupnya yang disertai dengan suku bunga tertentu sesuai dengan jangka waktu tertentu. Seperti halnya bank-bank lain, Bank Perkreditan Rakyat (BPR) Suryajaya Kubutambahan juga menyalurkan dana dalam bentuk kredit, salah satunya kredit konsumtif. Dalam pemberian kredit, bank ini berkonsentrasi pada masyarakat kalangan ekonomi menengah kebawah. Keberadaan bank ini dihadapkan dapat membantu masyarakat dalam berusaha sekaligus membantu pemerintah untuk meningkatkan pertumbuhan ekonomi nasional.

Tingkat suku bunga kredit konsumtif Bank Perkreditan Rakyat (BPR) Suryajaya Kubutambahan yang berlaku relatif berubah dari tahun ke tahun sesuai dengan kondisi dan keadaan yang ditentukan. Suku bunga dapat diartikan sebagai balas jasa yang diberikan oleh Bank atau Lembaga Keuangan lainnya kepada nasabah yang membeli atau menjual produknya. Bunga juga dapat diartikan sebagai harga yang harus dibayar kepada nasabah (yang memiliki simpanan) dan yang harus dibayar oleh nasabah kepada Bank (yang memiliki pinjaman). Baik bunga simpanan maupun bungan pinjaman merupakan komponen utama faktor biaya dan pendapatan bagi Bank. Bunga simpanan merupakan biaya dana yang harus dikeluarkan kepada nasabah sedangkan bunga pinjaman pendapatan yang diterima dari nasabah. Antara bunga simpanan dan bunga pinjaman masing-masing saling mempengaruhi satu sama lainnya. Apabila bunga simpanan tinggi, maka secara otomatis bunga pinjaman juga terpengaruh ikut naik dan demikian pula sebaliknya. Dalam hal ini, agar keuntungan yang diperoleh dapat maksimal maka pihak manajemen bank harus pandai dalam menentukan besar kecilnya komponen suku bunga maka akan dapat merugikan bank itu sendiri.

Suku bunga kredit konsumtif PT.Bank Perkreditan Rakyat Suryajaya Kubutambahan merupakan harga yang harus dibayar oleh nasabah kepada bank. Suku bunga kredit konsumtif yang berlaku pada PT.Bank Perkreditan Rakyat Suryajaya mengalami perubahan tiap tahun berikutnya sesuai dengan kondisi dan keadaan yang sudah ditentukan. Artinya dapat saja tingkat suku bunga kredit konsumtif tiba - tiba naik ataupun mengalami penurunan. Kebijakan tersebut berlaku menurut perundangan yang sudah ditetapkan oleh 
perintah melalui Bank Indonesia. Begitu juga dengan jumlah nasabah kredit konsumtif PT.Bank Perkreditan Rakyat Suryajaya Kubutambahan yang mengalami perubahan tiap tahun berikutnya. Hal ini disebabkan karena tingkat suku bunga kredit konsumtif yang berlaku ,mengalami penurunan ataupun mengalami kenaikan. Besar kecilnya bunga kredit konsumtif sangat dipengaruhi oleh besar kecilnya bunga simpanan. Semakin besar atau semakin mahal bunga simpanan, maka semakin besar pula bunga pinjaman dan demikian juga sebaliknya.

Tingkat suku bunga kredit konsumtif sangat memperngaruhi jumlah nasabah kredit konsumtif. Semakin kecil suku bunga kredit konsumtif maka semakin banyak orang atau nasabah yang tertarik meminjam dana di bank dalam bentuk kredit konsumtif. Demikian juga sebaliknya, semakin besar tingkat suku bunga kredit konsumtif maka masyarakatnya yang meminjam dana di bank dalam bentuk kredit konsumtif akan menurun. Untuk itu, dalam hal ini tingkat suku bunga kredit konsumtif dengan jumlah nasabah kredit konsumtif mempunyai hubungan yang erat.

Berdasarkan analisis data yang digunakan yaitu koefisien korelasi, koefisien determinasi dan analisi uji t- hitung dapat dilihat hubungan anatara tingkat suku bunga kredit konsumtif terhadap jumlah nasabah kredit konsumtif pada PT.Bank Perkreditan Rakyat Suryajaya Kubutambahan. Perhitungan analisis data koefisien korelasi didapatkan sebesar $-0,2342$ artinya bahwa ada hubungan yang negatif. Hal ini berarti apabila tingkat suku bunga kredit konsumtif meningkat maka jumlah nasabah kredit konsumtif akan menurun dan begitu juga sebaliknya apabila tingkat suku bunga kredit konsumtif menurun maka jumlah nasabah kredit konsumtif akan meningkat.

Perhitungan analisis data dengan menggunakan koefisien determinasi didapatkan sebesar $5,3 \%$, ini berarti jumlah nasabah kredit konsumtif dipengaruhi oleh tingkat suku bunga kredit konsumtif sebesar $5,3 \%$ dan sisanya sebesar $94,7 \%$ di pengaruhi oleh faktor jaminan. Sedangkan berdasarkan pengolahan data dengan menggunakan t-hitung didapatkan dari t-tabel, ini berarti bahwa ada penagruh antara tingkat suku bunga kredit konsumtif terhadap jumlah nasabah kredit konsumtif.

\section{Simpulan dan Saran}

\subsection{Simpulan}

Berdasarkan hasil analisis dan simpulan diatas, maka saran yang dapat diberikan adalah sebagai berikut :

1. Disarankan pada PT. Bank Perkreditan Rakyat Suryajaya Kubutambahan, agar penerapan tingkat suku bunga kredit sebaiknya tidak terlalu tinggi sehingga para pelaku usaha mikro tidak kesulitan untuk mendapatkan modal usaha.

2. PT. Bank Perkreditan Rakyat Suryajaya Kubutambahan diharapkan tetap meningkatkan aktivitas untuk selalu mempromosikan penyaluran dana melalui kredit konsumtif. Hal ini dapat dilakukan dengan cara memberikan penjelasan-penjelasan kepada masyarakat akan kelebihan atau keuntungan yang akan diperoleh masyarakat jika meminjam dana dalam bentuk kredit.

\subsection{Saran}

Berdasarkan hasil analisis yang telah diuraikan dalam BAB IV tentang Pengaruh Tingkat Suku Bunga Terhadap Jumlah Nasabah pada PT. Bank Perkreditan Rakyat Suryajaya Kubutambahan untuk tahun 2013-2015, maka dapat ditarik kesimpulan sebagai berikut:

1. Tingkat suku bunga kredit konsumtif PT. Bank Perkreditan Rakyat Suryajaya Kubutambahan mengalami perubahan tiap tahunnya. Pada tahun 2013 tingkat suku bunga kredit konsumtif mengalami perubahan sebanyak 2 kali, pada tahun 2014 tingkat suku bunga kredit konsumtif mengalami perubahan sebanyak 4 kali, dan pada tahun 2015 tingkat suku bunga kredit konsumtif tidak mengalami perubahan yaitu tetap sebesar $14 \%$. Hal tersebut diikuti juga dengan jumlah nasabah kredit konsumtif PT. Bank Perkreditan Rakyat Suryajaya Kubutambahan dari tahun 2013 sampai dengan tahun 2015 yang mengalami peningkatan setiap tahunnya. Hal ini disebabkan oleh tingginya 
minat masyarakat untuk meminjam uang dalam bentuk kredit konsumtif karena tingkat suku bunga yang relative lebih kecil tiap tahunnya. Berdasarkan hasil analisis data yang digunakan pengaruh tingkat suku bunga terhadap jumlah nasabah kredit konsumtif selama tahun 2013 sampai dengan tahun 2015 dapat dilihat sebagai berikut yaitu:

a. Perhitungan analisis korelasi didapatkan sebesar -0,2342 artinya adanya korelasi negative sebesar 0,2342 . Ini berarti bahwa ada hubungan yang negative. Hal ini berarti apabila tingkat suku bunga kredit konsumtif meningkat maka jumlah nasabah kredit konsumtif akan menurun dan begitu juga sebaliknya apabila tingkat suku bunga kredit konsumtif menurun maka jumlah nasabah kredit konsumtif akan meningkat.

b. Koefisien determinasi didapatkan hasil sebesar $5,3 \%$, ini berarti jumlah nasabah kredit konsumtif dipengaruhi oleh tingkat suku bunga sebesar $5,3 \%$ dan sisanya 94,7 dipengaruhi oleh faktor jaminan.

c.Dengan menggunakan t-hitung didapatkan sebesar -1,405 dan t-tabel sebesar 1,684. Karena t-hitung lebih besar dari t-tabel, maka $\mathrm{Ho}=0$ kita tolak, ini berarti ada hubungan antara tingkat suku bunga kredit konsumtif $(x)$ dengan jumlah nasabah kredit konsumtif $(\mathrm{y})$

\section{DAFTAR PUSTAKA}

Dajan, Anto. 1984. Pengantar Metode Statistik Jilid II. Jakarta : Salemba Empat.

Iswardono, Sp. 1981. Uang dan Bank. Yogyakarta : BPFE

Judisseno. Rimsky K. 2002. Sistem Moneter dan Perbankan Indonesia. Jakarta : PT. Raja Grafindo Persada.

Kasmir. 2000. Manajemen Perbankan. Jakarta : PT. Raja Grafindo Persada.

Rindjin, Ketut. 2000. Pengantar Perbankan dan Lembaga Keuangan Bukan Bank. Jakarta : PT. Gramedia Pustaka Utama.

Sri Susilo, Dkk. 2000. Bank Dan Lembaga Keuangan Lain. Yogyakarta : Salemba Empat.

Wirawan, Nata. 2001. Statistik 1. Denpasar : Keramas Emas.

Winarsunu, Tulus. 2002. Statistik, dalam penelitian Psikologi dan Pendidikan. Malang: UMM Press. 